(C) 1982. The Genetical Society of Great Britain

\title{
PYCNOGASTER CUCULLATA (CHARP.): A POLYTYPIC SPECIES OF TETTIGONIOIDEA WITH $X O$ AND NEO $X Y$ SEX DETERMINATION
}

\begin{abstract}
JOSÉ FERNANDEZ-PIOUERAS, ANTONIO RODRIGUEZ CAMPOS, CARLOS SENTIS CASTAÑO and FRANCISCO WANDOSELL JURADO Departamento de Genética, Facultad de Ciencias, Universidad Autónoma de Madrid, Mód. C-XV, Cantoblanco, Madrid-34, Spain
\end{abstract}

Received 19.i.81

\section{INTRODUCTION}

THE superfamily Tettigonioidea (long-horned grasshoppers) comprises more than 3500 species of which about 100 have been studied cytologically. Most of these show an $X O-X X$ sex chromosome mechanism and only six species are known to have a derived neo $X Y-X X$ system (Hewitt, 1979).

The Tettigoniid Pycnogaster cucullata (Charp.) is endemic to the Iberian Peninsula where it is found on clumps of Ilex. We have found populations of this species to be polytypic with respect of its sex chromosome system and this paper compares the structure of the $X O$ and neo $X Y$ forms.

\section{MATERIAL AND METHOdS}

We have studied seven populations of this species (fig. 1). The Truchas (Leon, Spain) population (49 males and one female) inhabits a marginal

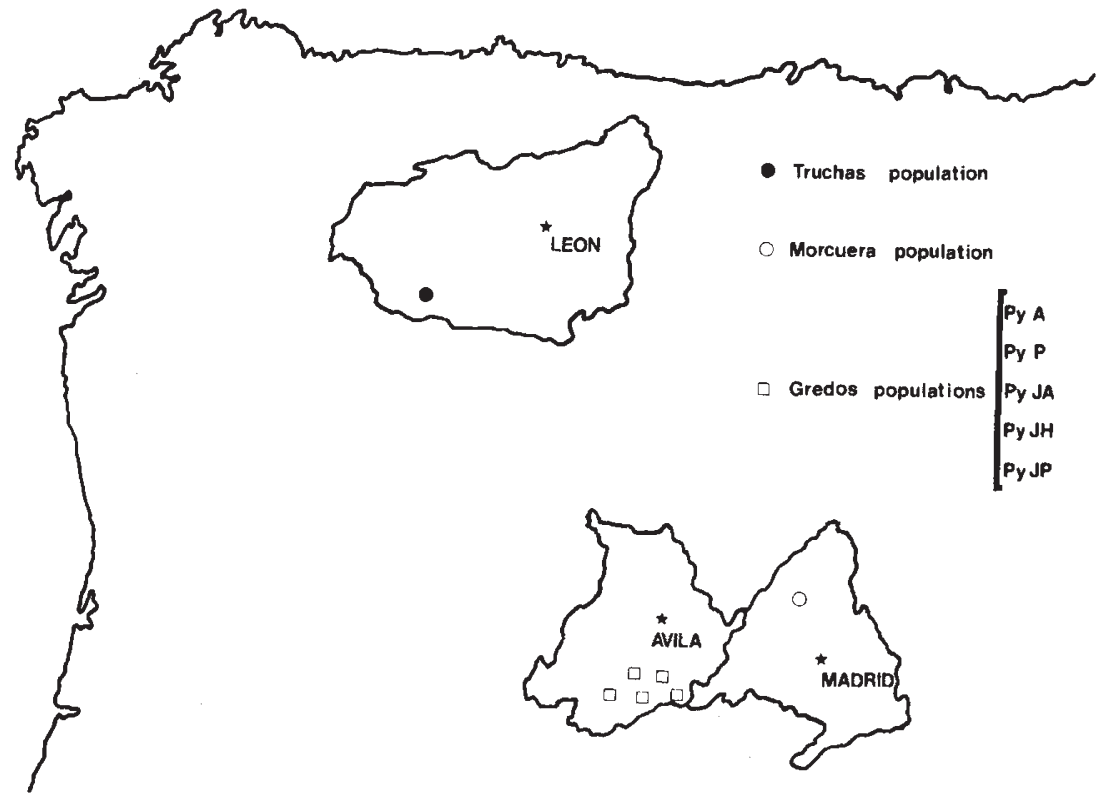

FIG. 1.-Populations studied. 
zone within the biogeographic region defined for the species and the individuals here differ morphologically from those collected in the central area of the species distribution (Morales Agacino, personal communication).

The individuals collected from the Morcuera population are similar to the Truchas, but this population is outside the range of this species (Gangwere and Morales Agacino, 1970).

Five populations have been collected in the Sierra de Gredos region, designated PyJP (nine males), PyP (ten males), PyA (five males), PyJA (five males) and $\mathrm{PyJH}$ (seven males).

A 0.05 per cent solution of colchicine was injected into the abdomen of males eight hours before the gastric caeca were removed. Both pretreated gastric caeca and untreated testis material of males were fixed for $2 \mathrm{~h}$ in alcohol-acetic $(3: 1)$ and then stored in 70 per cent alcohol. Conventional acetic orcein squash preparations were used together with C-banding preparations (Sumner, 1972).

\section{RESULTS}

\section{(i) The chromosome complement}

We have found two principal cytological races of $P$. cucullata. The basic karyotype of the Gredos populations (PyJP, PyJH, PyJA, PyA: $2 n$-male- = $28+X O$ and PyP: $2 n$-male- $=28+X O \pm 1 B$ ) consists of 29 chromosomes $(X O)$ in the male and 30 in the female $(X X)$ (fig. 2a). Two types of $\mathrm{M}_{2}$ chromosomes $\left(M_{2}\right.$ and $\left.M_{2}^{\prime}\right)$ have been seen with respectively one or two blocks of procentric C-heterochromatin (fig. 3b). A secondary constriction is present on this chromosome (fig. $2 a$ and $3 a$ and $b$ ).

The second basic karyotype of the Truchas (T) and Morcuera (M) populations $(2 n$-male- $=26+X Y \pm 1 B)$ differs from the former by the absence of the $\mathrm{M}_{2}$ pair and includes a neo $X X$ (female) neo $X Y$ (male) sex chromosome pair (fig. 2b). Two males from the $T$ population also carried a small $B$-chromosome. The neo $X$ chromosome is the largest in the complement and carries two secondary constrictions: one pericentromeric and the other in the distal section of its long arm (fig. 3c).

Although $P$. cucullata is characterized by a low heterochromatin content, there are three substantial blocks in the neo $X$ chromosome (fig. 3d). One of them, the largest, is proximal to the centromere and on the short arm. The neo $Y$ is slightly smaller than the short arm of neo $X$ and slightly larger than the $\mathrm{M}_{3}$ autosome. The centromeric and telomeric regions of the neo $Y$ also exhibit minor C-bands (fig. 3d). A comparison of the two chromosome races thus suggests that the neo $X Y$ system has been derived by an $\mathrm{M}_{2}-X$ centric fusion in a progenitor $X O-X X$ system similar to that in the Gredos populations. The precise size of the progenitor neo $Y$ is open to question since the short $\left(X_{R}\right)$ arm of the neo $X$ is longer than its free partner $Y$.

\section{(ii) Chiasma frequency}

Mean chiasma frequencies at diplotene of the different populations are given in table 1. Significant differences exist between the $X O$ and the neo 
Plate I
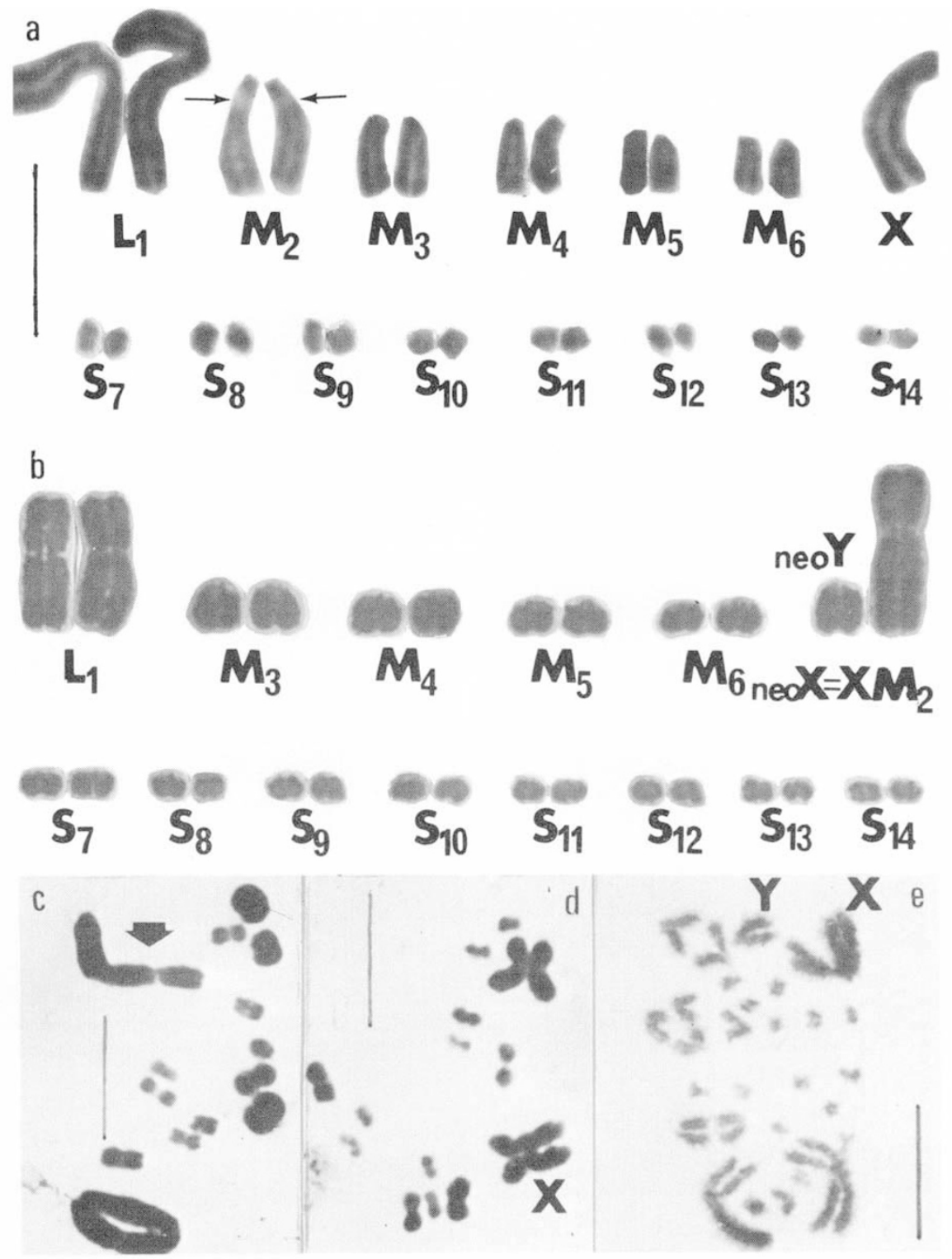

FIG. 2.-a. The basic karyotype of Pycnogaster cucullata in the Gredos populations. Note the secondary constriction in the $\mathrm{M}_{2}$ pair (arrow). b. Idem in the neo $X Y$ populations. Note the unequal size of the $X_{R}$ limb and the neo $Y$ chromosome. c. Metaphase I with the neo $X Y$ sex bivalent showing a single terminal association (arrow). d. Metaphase II with a neo $X$ chromosome (arrow). e. Reductional segregation of the neo $X Y$ sex bivalent at anaphase $I$. Bars in all figures represent $10 \mu \mathrm{m}$. 


\section{Plate II}

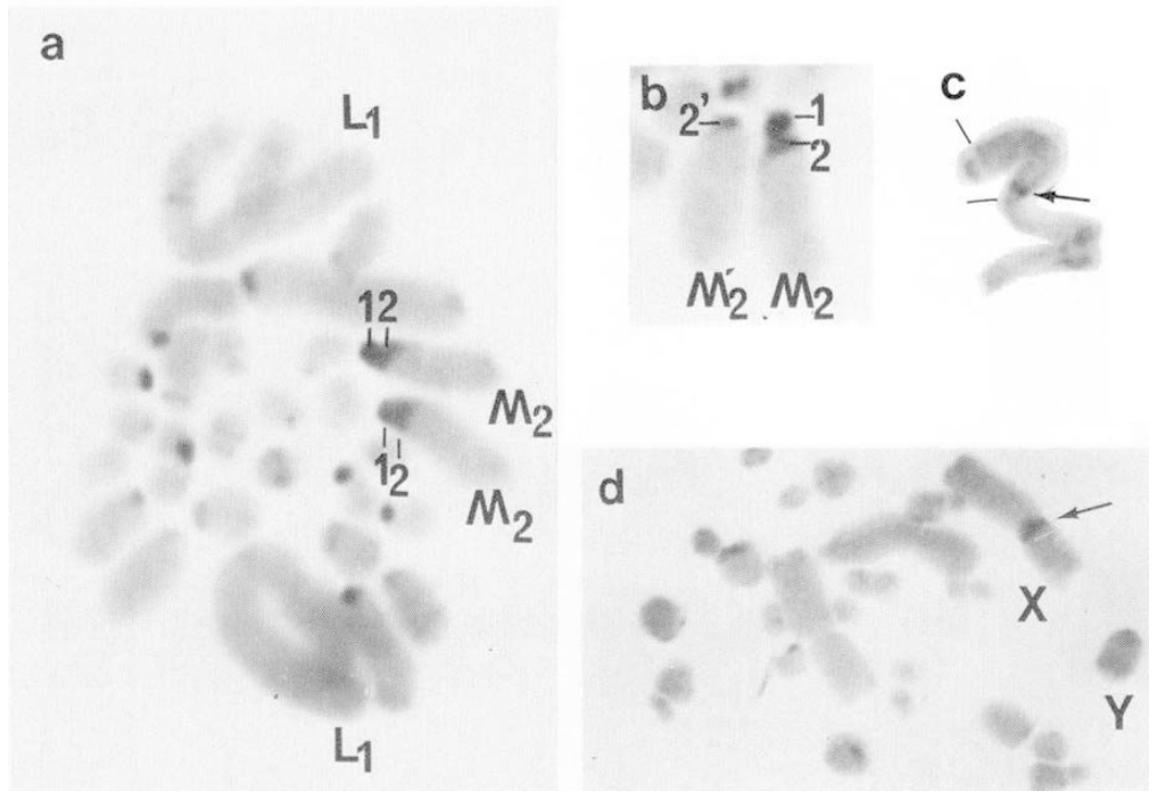

Fig. 3.-a. The C-band pattern in a C-mitotic metaphase of the $X O$ form. $b$. The two $\mathrm{M}_{2}$ types found in the $X O$ state. c. An early diplotene neo $X Y$ sex bivalent. Note the presence of a subterminal chiasma, a proximal C-positive block (arrow) and two secondary constrictions (bars). d. The C-band pattern of the neo $X Y$ state. 
TABLE 1

Mean cell chiasma scores in the different populations of Pycnogaster cucullata. The neo $X Y$ chiasma is added to the $M$ total

\begin{tabular}{|c|c|c|c|}
\hline Populations & $\begin{array}{c}\text { Chromosomal } \\
\text { types }\end{array}$ & Individuals & $\begin{array}{l}\text { Mean cell } \\
\text { chiasma }\end{array}$ \\
\hline PyT & $\underset{Y Y}{X Y}$ & 10 & $16 \cdot 65 \pm 0.3$ \\
\hline PyM & $\begin{array}{c}X Y+B \\
X Y\end{array}$ & $\begin{array}{l}2 \\
9\end{array}$ & $\begin{array}{l}18 \cdot 35 \pm 0 \cdot 07 \\
15 \cdot 52 \pm 0 \cdot 35\end{array}$ \\
\hline PyP & $X O$ & 8 & $18.34 \pm 0.68$ \\
\hline & $X O+B$ & 2 & $19.45 \pm 0.77$ \\
\hline PyJP & XO & 9 & $18.40 \pm 0.67$ \\
\hline PyA & XO & 5 & $18.42 \pm 0.67$ \\
\hline PyJA & $X O$ & 6 & $18.56 \pm 0.64$ \\
\hline РyJH & $X O$ & 7 & $18.41 \pm 0.96$ \\
\hline
\end{tabular}

$X Y$ forms $(P<0 \cdot 005)$. There is also a significant difference between karyotypes and a $t$-test shows that this is due to the $B$-chromosome individuals of the Truchas population $\left(t_{1,2}=2.61<0 \cdot 05\right)$. A Snedecor's $F$ distribution revealed that the $B$-chromosomes in $P$. cucullata significantly decrease the between cell variance $(P<0 \cdot 01)$.

\section{Discussion}

In $P$. cucullata there is an obvious inequality in length between the neo $Y$ and its homologous arm $\left(X_{R}\right)$ in the neo $X$. This inequality is related to the presence of a proximal C-block and a secondary constriction in the $X_{R}$ arm which is not represented in the neo $Y$ (fig. $3 \mathrm{c}$ and d). Most of the recorded cases of neo $X Y$ systems postulate a neo $Y$ that has been modified by deletion or sometimes by duplication and translocation following the centric fusion event. By contrast in two of the six neo $X Y$ mechanisms described in the superfamily Tettigonioidea the $Y$ is considerably larger than the $X_{R}$ arm (Hewitt, 1979). The present neo $Y$ chromosome may have arisen from either of the two $\mathrm{M}_{2}$ types. If the neo $Y$ were to have originated from the smaller of these $\left(\mathbf{M}_{2}^{\prime}\right)$ (fig. $3 b$ ), which only posseses one C-band, this would involve loss of the secondary constriction together with part of the $\mathrm{C}$-band so accounting for the smaller size of this band on the neo $Y$.

The chiasma difference between the $X O$ and the $X Y$ populations of $P$. cucullata cannot simply be an effect of the fusion differences that distinguishes them, since this difference is due to the higher number of chiasmata present in both $\mathrm{L}$ and $\mathrm{M}$ bivalents of the Gredos populations. Nevertheless, the unfused progenitor of the neo $Y / X_{R}$ (the $\mathrm{M}_{2}$ bivalent) does make a contribution to this difference forming both ring and rod bivalents in all the Gredos populations, and these include obviously interstitial chiasmata. By contrast, in Truchas and Morcuera, the neo $X Y$ never forms a ring bivalent.

In Podisma pedestris the frequency of proximal chiasmata, in the neo $X Y$ forms, has been reduced probably as a direct consequence of the fusion itself (Hewitt and John, 1972). Thus in both Podisma and Pycnogaster there is a reduction in the chiasma frequency of the autosome involved in the fusion coupled with a repositioning of chiasmata to distal sites in the product of the fusion (fig. 3c). 
Chiasma formation may or may not be affected by $B$-chromosomes (John, 1973; Schroeter and Hewitt, 1974). Both responses have been found in Pycnogaster. Here only the $B$-chromosomes of the Truchas population increased the mean chiasma frequency. The decreased between-cell variance for chiasma frequency suggests a stabilising role for the $B$-chromosomes in populations. The polytypic state of this species suggests that the neo $X Y$ system may be of recent origin.

According to Gangwere and Morales Agacino (1970) the central area of this species is Central Portugal. If this is so, it is possible that the two neo $X Y$ populations (Truchas and Morcuera) represent two different lines in the expansion of a more central original neo $X Y$.

Acknowledgments. - We wish to thank Prof. Bernard John and Amadeo Sañudo for their critical reading of part of this manuscript; Enrique Rojo García, Jose Luis Rodriguez and Carlos García de la Vega for their technical assistance. Finally, we owe a very clear debt to Eugenio Morales Agacino for taxonomic determination of the material studied by us; without such assistance this paper would not have been written.

\section{REFERENCES}

GANGWERE, S. K., AND MORALES AGACINO, E. 1970. The biogeography of Iberian orthopteroids. Misc. Zool. II, 1-67.

HEWITT, G. M. 1979. Grasshoppers and crickets. Animal Cytogenetics, Vol. 3: Insecta 1, Orthoptera. Gebrüder Borntraeger, Berlin, Stuttgart.

HEWITT, G. M., AND JOHN, B. 1972. Inter-population sex chromosome polymorphism in the grasshopper Podisma pedestris. II. Population parameters. Chromosoma (Berl.), 37, 23-42.

JOHN, B. 1973. The cytogenetic systems of grasshoppers and locust. II. The origin and evolution of supernumerary segments. Chromosoma (Berl.), 44, 123-146.

SCHROETER, G. L., AND HEWITT, G. M. 1974. The effects of supernumerary chromatin in three species of grasshoppers. Can. J. Genet. Cytol., 16, 285-296.

SUMNER, A. T. 1972. A simple technique for demonstrating centromeric heterochromatin. Exp. Cell Res., 75, 304-306. 